\title{
Effect of a late evening meal on nitrogen balance in patients with cirrhosis of the liver
}

\author{
G R Swart, M QZZillikens, J K|van Vuure, J W Ojvan den Berg \\ Abstract \\ Objective-To assess whether a late evening meal \\ would improve nitrogen balance in patients with \\ cirrhosis of the liver. \\ Design-Randomised crossover study of meal \\ schedules comparing three meals a day with four or \\ six meals a day, the four and six meal schedules both \\ including a late evening meal (2300). \\ Setting-Metabolic ward. \\ Patients - Seven men and two women aged 34-66 \\ with cirrhosis of the liver (Child's grade B). \\ Interventions-Patients spent two seven day \\ periods in the ward. For five days of each period they \\ explained by reduced liver glycogen stores, the early \\ onset of gluconeogenesis from amino-acids at night \\ leading to an additional amino acid loss. ${ }^{5}$ We recently \\ showed that nocturnal glucose supplementation does \\ indeed reduce raised protein turnover rates and leads \\ to a better nitrogen balance in patients with cirrhosis. ${ }^{6}$ \\ As nocturnal glucose feeding is not easy to continue in \\ practice we studied the effects of meal frequency \\ on nitrogen balance, on the assumption that a late \\ evening meal would delay the otherwise early onset of \\ nocturnal amino acid breakdown for gluconeogenesis; \\ it would thus reduce amino acid loss and improve \\ nitrogen balance.
} received, in random order, isonitrogenous isocaloric diets supplied in three meals a day and in four or six meals a day.

Main outcome measure-Nitrogen balance, calculated as the difference between dietary intake and the total of urinary, faecal, and integumental nitrogen loss.

Results-Faecal nitrogen loss was no different between three meals a day and four or six meals a day. On both four and six meals a day, however, patients had nitrogen balances that were more positive (or less negative) than on three meals a day $(1.26$ (SD 2.1) g/24h v 0.26 (2.2) g/24 h, p<0.01). Six meals a day did not produce significantly better improvements in nitrogen balance than four meals a day.

Conclusions-A late evening meal seemed to improve the efficiency of nitrogen metabolism, but longer term studies are needed to assess whether this leads to a better nutritional state.

\section{Introduction}

Patients with cirrhosis of the liver are often malnourished.' They need more protein to maintain nitrogen equilibrium ${ }^{23}$ than healthy people, ${ }^{4}$ and their rates of protein turnover-both synthesis and breakdown-are increased. ${ }^{5}$ Nevertheless, protein intolerance can lead to portosystemic encephalopathy, and dietary protein may have to be reduced to levels below those needed to maintain nitrogen balance.

Increasing the efficiency of nitrogen metabolism would help to overcome the therapeutic dilemma of choosing between protein need and protein tolerance; it might also improve the nutritional state. We hypothesized that the high protein requirements could be

Dr Swart

BrMed F 1989;299:1202-3

\section{Patients and methods}

Nine patients with Child grade B cirrhosis of the liver confirmed at biopsy were studied (table I). During the study they stayed in a metabolic ward after admission to a medical ward for clinical stabilisation. They had no fever, no signs of infection, and no ascites or portosystemic encephalopathy; they had not recently drunk alcohol. Their mean age was 54 (range 34-68) years. The body mass index (Quetelet index) was $26 \cdot 4$ (range $20 \cdot 2-34.3) \mathrm{kg} / \mathrm{m}^{2}$.

The patients were admitted to a metabolic ward for two consecutive periods of seven days. In each period two days were spent on metabolic equilibration and nitrogen balance was measured over the following five days. During the two periods the patients consumed isonitrogenous isocaloric diets in two of three schedules. All the patients received three meals a day in one period; in the other they received either four meals a day or six meals a day. The order of the meal schedules was random. Meals were given at 0800 , 1200 , and 1700 (three meal periods); $0800,1200,1700$, and 2300 (four meal periods); or $0800,1000,1200$, 1500,1700 , and 2300 (six meal periods). Nitrogen balance was calculated as the difference between the measured dietary nitrogen intake and the total of the measured daily urinary nitrogen excretion, the measured faecal nitrogen loss (five day pools), and the integumental nitrogen loss, estimated to be $0.5 \mathrm{~g} / 24 \mathrm{~h} .{ }^{7}$ To correct for incomplete collection of faeces we gave the patients $1200 \mathrm{mg}$ of polyethylene glycol daily and determined faecal polyethylene glycol excretion.

Diets-The total caloric content of the diets was chosen according to each patient's appetite as found by dietary questioning (table II). A mean of $114 \mathrm{~kJ} / \mathrm{kg} /$ day (range 80-139) was chosen. The protein content of the diet was decided on by the physician: a mean of $67 \cdot 4$ (range 59.6-99.0) g/day was given. The late evening meal was scheduled to contain about $20 \%$ of the total daily energy and protein intake (table II); on average it supplied $17 \%$ of the energy and $20 \%$ of the protein.

Laboratory procedures-Urinary nitrogen was measured in an automatic nitrogen analyser (ANA 1400; Carlo Erba, Milan, Italy) by the Dumas procedure. The coefficient of variation for repeated measurements with this instrument is $1 \cdot 7 \%$. Faecal samples were destroyed by acid and heat; the remaining clear solution was analysed for nitrogen content in 
TABLE II-Energy and protein content of the diets; for the whole day and for the late evening meal

\begin{tabular}{|c|c|c|c|c|}
\hline \multirow[b]{2}{*}{ Case No } & \multicolumn{2}{|c|}{ Total per day } & \multicolumn{2}{|c|}{ Evening meal } \\
\hline & Energy $(\mathbf{M J})$ & Protein $(\mathrm{g})$ & Energy $(\mathrm{MJ})$ & Protein $(\mathrm{g})$ \\
\hline 1 & $8 \cdot 18$ & $60 \cdot 2$ & $1 \cdot 76$ & $11 \cdot 4$ \\
\hline 2 & $8 \cdot 64$ & $59 \cdot 6$ & 1.65 & $13 \cdot 9$ \\
\hline 3 & $7 \cdot 74$ & $60 \cdot 0$ & 1.63 & $14 \cdot 1$ \\
\hline 4 & $9 \cdot 73$ & $60 \cdot 5$ & $2 \cdot 01$ & $13 \cdot 5$ \\
\hline 5 & $8 \cdot 17$ & $63 \cdot 4$ & 1.85 & $5 \cdot 3$ \\
\hline 6 & $9 \cdot 23$ & $60 \cdot 7$ & $1 \cdot 19$ & $15 \cdot 3$ \\
\hline 7 & $9 \cdot 43$ & $64 \cdot 5$ & 0.91 & $17 \cdot 0$ \\
\hline 8 & $7 \cdot 96$ & $99 \cdot 0$ & 0.65 & $15 \cdot 0$ \\
\hline 9 & $8 \cdot 84$ & $79 \cdot 0$ & $1 \cdot 50$ & $13 \cdot 0$ \\
\hline Mean & 8.66 & $67 \cdot 4$ & $1 \cdot 46$ & $13 \cdot 2$ \\
\hline
\end{tabular}

TABLE III - Daily nitrogen balances according to numbers of meals per day

\begin{tabular}{cccc}
\hline & \multicolumn{2}{c}{ Nitrogen balance $(g / 24 \mathrm{~h})$} \\
\cline { 2 - 4 } Case & 3 & 4 & 6 \\
No & Meals & Meals & Meals \\
\hline 1 & -0.45 & $+0.18^{\star}$ & \\
2 & $-1.25^{\star}$ & -0.87 & \\
3 & $-2.53^{\star}$ & -1.80 & \\
4 & $-0.08^{\star}$ & +0.84 & \\
5 & $+1.81^{\star}$ & +2.80 & \\
6 & $-2.39^{\star}$ & +0.78 \\
7 & +0.73 & & $+0.97^{\star}$ \\
8 & +2.96 & $+4.51^{\star}$ \\
9 & +3.62 & & $+3.98^{\star}$
\end{tabular}

$\star$ First dietary period. the same automatic nitrogen analyser. The results obtained with this procedure were found to be $103 \%$ of those with the classic Kjeldahl technique.

Statistics-The data are presented as means (and standard deviations). For statistical evaluation we used Student's $t$ test for uneven numbers of observations and the Wilcoxon rank sum test for paired observations.

\section{Results}

The diets were well tolerated, and the patients showed no preference for either meal schedule. Faecal nitrogen loss was no different between the three meals a day schedule and the four or six meals a day schedule $(2.01(0.62) \mathrm{g} / 24 \mathrm{~h} v 2 \cdot 13(0.56) \mathrm{g} / 24 \mathrm{~h})$. On three meals a day both positive and negative nitrogen balances were found. There was no significant correlation between the nitrogen balance and the serum albumin or bilirubin concentration, which was taken as a marker of the severity of the liver disease.

On four meals a day three patients were in positive and two in negative nitrogen balance; on six meals a day all four patients were in positive nitrogen balance. On both four and six meals a day nitrogen balances were consistently more positive or less negative than on three meals a day $(1 \cdot 26(2 \cdot 1) \mathrm{g} / 24 \mathrm{~h} v 0 \cdot 26(2 \cdot 2) \mathrm{g} / 24 \mathrm{~h}$ $\mathrm{p}<0.01$ Wilcoxon test; table III); the mean difference was $1 \cdot 0(0 \cdot 3) \mathrm{g} / 24 \mathrm{~h}$ (range $0 \cdot 24-3 \cdot 17)$. Six meals a day did not produce a significantly better improvement in nitrogen balance than four meals a day $(1.33(0.68) \mathrm{g} /$ $24 \mathrm{~h} v 0 \cdot 73(0 \cdot 11) \mathrm{g} / 24 \mathrm{~h})$.

\section{Discussion}

In this study nitrogen balance was always more positive, or less negative, on isonitrogenous and isocaloric diets when a late evening meal was given. The additional nitrogen retention with an extra meal at bedtime was $1 \cdot 0 \mathrm{~g} / 24 \mathrm{~h}$ (range $0 \cdot 24-3 \cdot 17$ ) on average. Thus the efficiency of nitrogen metabolism seemed to improve when a late evening meal was given. A retention of $1 \mathrm{~g}$ nitrogen, when incorporated into protein, is roughly equivalent to $6.25 \mathrm{~g}$ of protein or about $30 \mathrm{~g}$ of lean tissue. If such a dietary regimen could be continued over longer periods a better nutritional state and an increase in lean body mass could be expected. Such improved efficiency would be especially useful in patients who need to take protein restricted diets to prevent portosystemic encephalopathy or in those with signs of protein-energy malnutrition. Further clinical studies, including body composition measurements, will, however, be needed to assess whether this effect of meal frequency on nitrogen balance is clinically important. We are not aware of previous reports of studies on the effects of meal frequency on nitrogen balance in patients with cirrhosis of the liver. In healthy people meal frequency does not seem to influence nitrogen balance. ${ }^{8-10}$

Our results support the hypothesis that increased protein requirements in cirrhosis might result from additional amino acid loss caused by the early onset of nocturnal gluconeogenesis from amino acids, in turn caused by small liver glycogen stores. ${ }^{5}$ Might the effects on nitrogen balance also be obtained by giving more frequent small meals only during the daytime? Such a schedule, excluding a late evening meal, has not been tested. Although we did not find a statistically significant difference in nitrogen balance between the schedule with four meals a day and that with six meals (in which five of the six meals were taken during the daytime), the numbers of observations were too small to reach a firm conclusion. A greater absorption of nutrients as a result of more frequent presentation of food to the gut probably does not explain the better nitrogen balance since faecal nitrogen loss was the same with three and four and with three and six meals a day.

Additional studies of the long term effects of a higher meal frequency on body composition and clinical complications in patients with cirrhosis are needed. The clinical implication of these findings is that cirrhotic patients should be advised to take an additional meal at bedtime.

1 Silk DBA. Malnutrition in liver disease and its relationship to hepatic encephalopathy. Acta Chir Scand 1981;147(suppl 507):106-10.

Gabuzda GJ, Davidson CS. Protein metabolism in patients with cirrhosis of the liver. Ann NY Acad Sci 1954;57:776-85.

3 Swart GR, van den Berg JWO, van Vuure JK, Rietveld T, Wattimena DL, Frenkel M. Minimum protein requirements in liver cirrhosis determined by nitrogen balance measurements at three levels of protein intake. Clinical Nutrition (in press)

4 World Health Organisation. Energy and protein requirements. WHO Technical Report Series 1985;724:81-2.

5 Swart GR, van den Berg JWO, Wattimena DL, Rietveld T, van Vuure JK, Frenkel $M$. Elevated protein requirements in cirrhosis of the liver investigated by whole body protein turnover studies. Clin Sci 1988;75 101-7.

6 Zillikens MC, van den Berg JWO, Swart GR. The effects of nocturnal oral glucose supplementation on protein turnover in patients with cirrhosis of the liver. I Hepatol 1986;3(suppl 1):S79.

7 Calloway DH, Odell ACF, Margen S. Sweat and miscellaneous nitrogen losses in human balance studies. 7 Nutr 1971:101:775-86.

8 Irwin MI, Feeley RM. Frequency and size of meals and serum lipids, nitrogen and mineral retention, fat digestibility, and urinary thiamine and riboflavine in young women. Am $\mathcal{J}$ Clin Nutr 1967;20:816-24.

9 Swindells.YE, Holmes SA, Robinson MF. The metabolic response of youn women to changes in the frequency of meals. Br f Nutr 1968;22:667-80.

10 Young CM, Hutter LF, Scanlan SS, Rand CE, Lutwak E, Simko V. Metabolic effects of meal frequency on normal young men. 7 Am Diet Assoc 1972;61:391-8

(Accepted 11 September 1989)

\section{ONE HUNDRED YEARS AGO}

It was to be expected that the coroner's inquest into the cause of death of the boy Sydney Bolton would terminate in a charge of murder against Mrs. Winter, inasmuch as the death had been clearly proved to be due to arsenical poisoning, which occurred whilst the boy was under her sole charge; moreover, and it was a very ugly feature in the case, she had insured the boy's life. Since the commencement of the inquiry, the bodies of two other persons have been exhumed, and the coroner's jury have returned a verdict of wilful murder in all three cases against her daughter, Mrs. Frost. In the face of these facts it behoves us to see what steps can be taken to blot out the particular form of danger thus brought into consideration, and this irrespective of the question whether the particular persons charged are or are not those guilty of the crime. In the first place it is clear that the law forbidding anyone to insure another's life must be stringently enforced, which at present is evidently not the case. It would probably be a good plan if a special form of death-certificate were made compulsory in all cases where the life had been insured, such certificate giving the fullest particulars as to the symptoms and duration of illness, mode of onset, etc., instead of as at present the bare name of the disease; the insurance office might be obliged to supply the certificate and to pay a special fee for it. An additional, and indeed the only absolute, safeguard, would be that a post-mortem examination, by a competent pathologist, should be required in all cases where the life of the deceased had been insured. (British Medical Fournal 1889;ii:87) 